\title{
Phytocannabinoids and endocannabinoids: different in nature
}

\author{
Mauro Maccarrone ${ }^{1,2}$ D
}

Received: 6 July 2020 / Accepted: 14 September 2020 / Published online: 15 October 2020

(c) The Author(s) 2020

\begin{abstract}
Cannabis is one of the earliest cultivated plants, of which Cannabis sativa and Cannabis indica are the most widespread and best characterized species. Their extracts contain (phyto)cannabinoids (pCBs) of therapeutic interest, such as $\Delta^{9}$ tetrahydrocannabinol and cannabidiol, along with many other compounds, so that there is no "one cannabis" but several mixtures even from the same plant. This complexity is mirrored, or even exceeded, by the complexity of the molecular targets that pCBs find in our body, most of which belong to the so-called "endocannabinoid (eCB) system". Here, we describe the major $\mathrm{pCBs}$ and the main components of the $\mathrm{eCB}$ system to appreciate their differences and mutual interactions, as well as the potential of using $\mathrm{pCB} / \mathrm{eCB}$-based drugs as novel therapeutics to treat human diseases, both in the central nervous system and at the periphery. Moreover, we address the question of the evolution of pCBs and eCBs, showing that the latter compounds were the first to appear in nature, and that the former substances took a few million years to mimic the threedimensional structures of the latter, and hence their biological activity in our body.
\end{abstract}

\section{Graphic abstract}

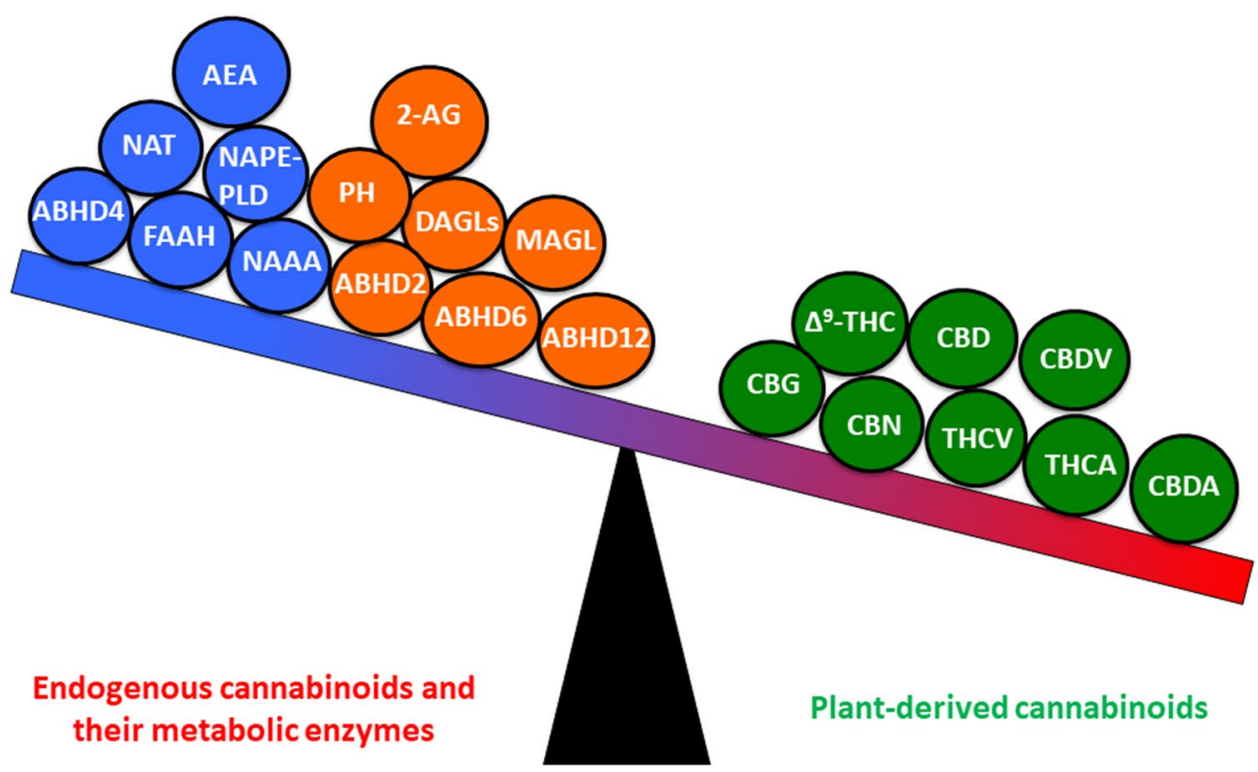

This article is a peer-reviewed paper originated from presentations at the Conference CANNABIS AND CANNABINOIDSHISTORY, USES, AND SOCIO-ECONOMICAL IMPLICATIONS OF A CONTROVERSIAL PLANT held at Accademia Nazionale dei Lincei in Rome, 20 December 2019 organized by Vincenzo Di Marzo (Coordinator), Gennaro Marino, Jacopo Meldolesi, Daniela Parolaro.

Extended author information available on the last page of the article 
Keywords Cannabinoid receptor $\cdot$ Bioactive lipid $\cdot$ Metabolic enzyme $\cdot$ Pharmacophore $\cdot$ Signal transduction $\cdot$ Vanilloid receptor

\section{Introduction}

Cannabis is one of the earliest cultivated plants. When it is of industrial utility and culinary value, it is generally termed hemp; when it is bred for medical or recreational purposes, it is called marijuana. In both cases, the female plant produces a significant amount of bioactive and psychoactive compounds, but the existence of different species and cultivars of cannabis must be taken into account to evaluate their impact on health. Cannabis sativa and Cannabis indica are the most widespread and best characterized species of cannabis, and their extracts contain (phyto)cannabinoids (pCBs) of therapeutic interest, such as $\Delta^{9}$-tetrahydrocannabinol ( $\Delta^{9}$ THC) and cannabidiol (CBD), both shown in Table 1. Yet, the effect of cannabis extracts does not depend only on the amount of $\Delta^{9}$-THC and CBD, but also on the presence and concentration of $>110$ additional pCBs, and $>440$ nonphytocannabinoid compounds like terpenoids, flavonoids and sterols (Sohly et al. 2014; Solymosi and Köfalvi 2017). Among the pCBs, the following classes have been clearly detected in cannabis extracts: (1) in abundant amounts $\Delta^{9}$ THC and its analogs (including $\Delta^{8}$-tetrahydrocannabinol and $\Delta^{9}$-tetrahydrocannabivarin), CBD and its analogs (including the propyl derivative cannabidivarin), cannabinol and its analogs (including the propyl derivative cannabivarin), cannabigerol and its analogs; (2) in less abundant amounts cannabinodiol, cannabichromene, cannabicyclol, cannabielsoin, cannabitriol (ElSohly et al. 2017; Morales et al. 2017), as well as others like varinic (short aliphatic chain) and acidic (bearing carboxylic groups) derivatives of the major pCBs. To date, understanding of the pharmacological properties of these pCBs have only scratched the surface (Franco et al. 2020; Russo 2018). Therefore, it should be appreciated that the term "(phyto)cannabinoids" serves to cluster different plant-derived lipophilic compounds, which are clearly distinguishable from other pharmacologically related, but structurally different, natural and synthetic compounds (Ligresti et al. 2016; Pertwee 2014).

It is also remarkable that different cannabis extracts may have a largely different chemical profile (i.e., they may be different "chemovars"), which means that they may contain different components and/or different amounts of the same constituents. In addition, the modes of cultivation, harvest, extraction of active principles, and of their administration routes to subjects, may further affect the final chemical composition, clearly suggesting that there is no "one cannabis" but several mixtures even from the same plant (Friedman et al. 2019). This is the reason why there is still little understanding of the pharmacological efficacy of cannabis extracts, and indeed remaining uncertainties represent a warning for the clinical applications of these natural compounds (Friedman et al. 2019). The pCBs that have been characterized for potential medical applications, and for which cellular targets have been clearly identified, are reported in Table 1 (for more details, see ref. 10).

Unsurprisingly, marijuana is surrounded by controversies, debates and misconceptions related to its medical potential, legalization and long-term health consequences. To date, marijuana is the most widely used recreational drug in Western countries, and is consumed by $\sim 3 \%$ of the world population ( 185 million individuals) (United Nations Office on Drugs and Crime (2017). The advent of legalized cannabis in multiple regions of the United States, and elsewhere around the world, have raised additional and urgent concerns about its potential hazard to health. Nevertheless, research on the therapeutic potential of cannabis extract-based drugs suggests them to be clinically useful in a wide range of pathological conditions, including neurological (Friedman et al. 2019; Cristino et al. 2020) and psychiatric disorders (Cohen et al. 2019). Conversely, repeated cannabis use has been associated with short-term and long-term side effects, including cognitive alterations, psychosis, schizophrenia and mood disorders (Cohen et al. 2019), as well as with respiratory and cardiovascular diseases (Maccarrone et al. 2015).

\section{Metabolism of phytocannabinoids}

Phytocannabinoids are synthesized via metabolic pathways that start from farnesyl diphosphate to produce geranyl diphosphate, that is then condensed with olivetolic acid in a reaction catalysed by cannabigerolic synthase. From the cannabigerolic acid product, a number of pCBs are generated (Solymosi and Köfalvi 2017; Schafroth and Carreira 2017), as depicted in Fig. 1 a.

It is very important that $\mathrm{pCBs}$ cannot be degraded by our body. Yet, biotransformation of $\Delta^{9}$-THC may occur primarily within the liver by hydroxylation and oxidation reactions catalyzed the cytochrome $\mathrm{P} 450$ subfamily $2 \mathrm{C} 9$ (CYP2C9) enzymes, which play a major role in rodents and humans (Watanabe et al. 1993, 2007). Such a "phase I metabolism" involves hydroxylation of $\Delta^{9}$-THC to its primary metabolite 11-hydroxy- $\Delta^{9}$-tetrahydrocannabinol (11OH-THC), that in turn undergoes further oxidation by other liver enzymes to the inactive secondary metabolite 11-nor-9-carboxy- $\Delta^{9}$-tetrahydrocannabinol (11-COOHTHC, or THC-COOH), as shown in Fig. 2b. The latter substance is then biotransformed further during "phase II 
Table 1 Major plant-derived and endogenous cannabinoids

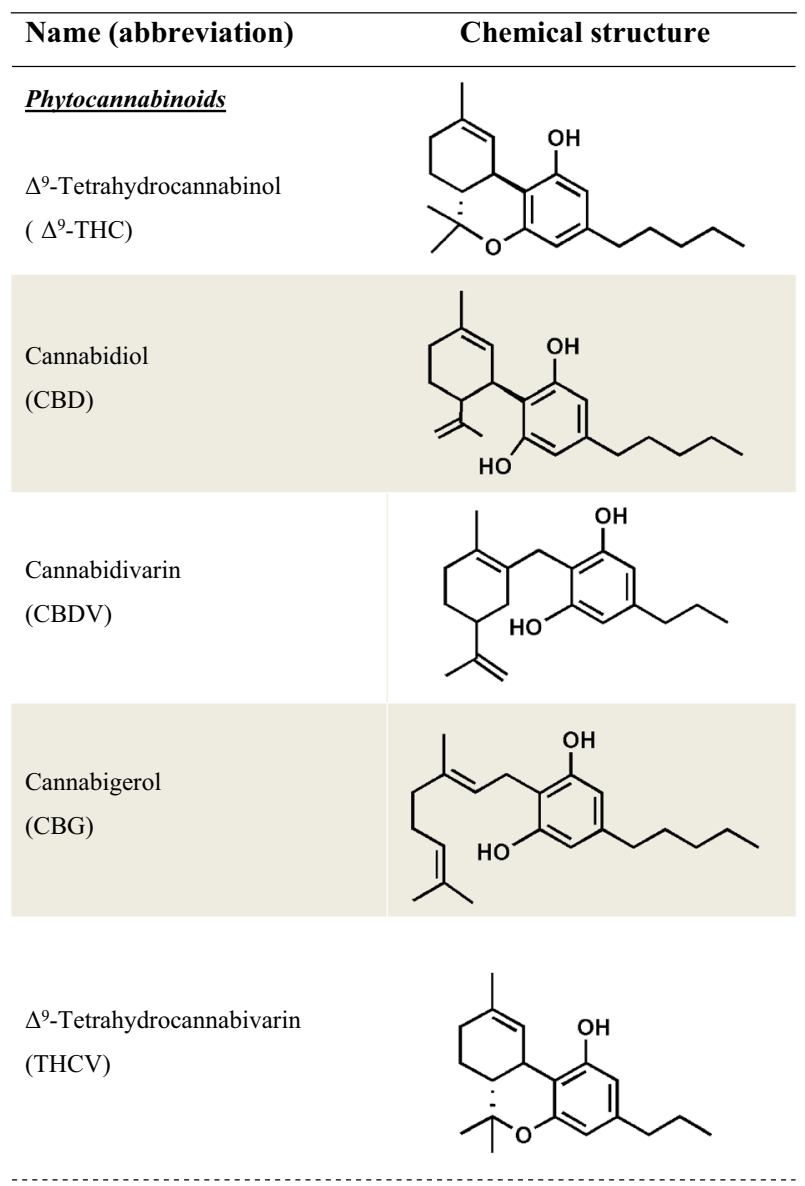

o-6 Endocannabinoids

$N$-Arachidonoylethanolamine

(Anandamide, AEA)

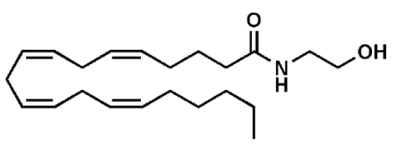

2-Arachidonoylglycerol

(2-AG)

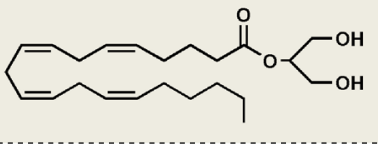

w-3 Endocannabinoids

$N$-Eicosapentaenoylethanolamine

(EPEA)
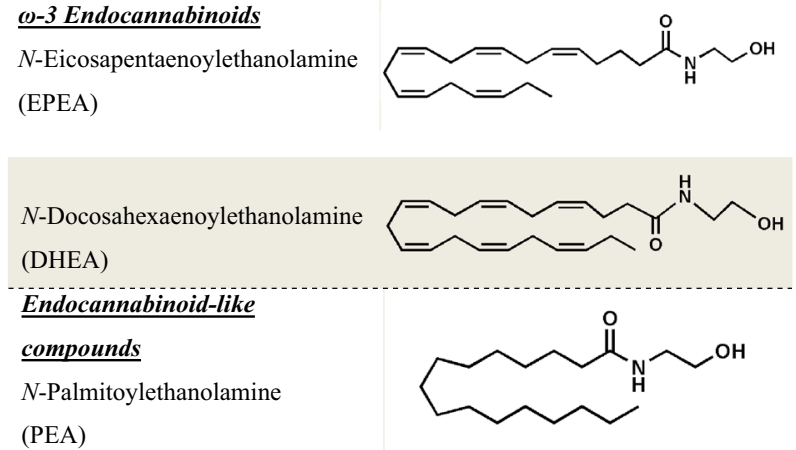

$\mathrm{N}$-Oleoylethanolamine

(OEA)

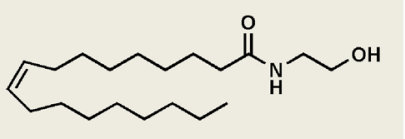

metabolism" by UDP-glucuronosyltransferase (UGTase)dependent glucuronidation, producing a water-soluble glucuronide which can be more easily excreted by the body. Much in the same way, $\Delta^{9}$-THC degradation product cannabinol (CBN) can be converted by CYP2C9 into $11 \mathrm{OH}-$ CBN (Fig. 1b).

As mentioned above, pCBs are endowed with many pharmacological properties, due to their ability to hit and modulate (as agonists, inverse agonists, antagonists, or even positive or negative allosteric modulators) different cellular targets (Morales et al. 2017; Turner et al. 2017; Friedman et al. 2019; Cristino et al. 2020; Hanuš et al. 2016). Indeed, it should be appreciated that the complexity of cannabis extracts is mirrored, and possibly even exceeded, by the complexity of the molecular targets that they find in our body, most of which belong to the so-called "endocannabinoid system" described in the following section.

\section{Metabolism of endocannabinoids}

It is well-established that $\Delta^{9}$-THC binds to and activates specific $\mathrm{G}$ protein-coupled receptors, known as type-1 $\left(\mathrm{CB}_{1}\right)$ and type-2 $\left(\mathrm{CB}_{2}\right)$ cannabinoid receptors, which endogenously are triggered by ligands that were identified in the ' $90 \mathrm{~s}$ as anandamide ( $N$-arachidonoylethanolamine, AEA) (Devane et al. 1992) and 2-arachidonoylglycerol (2-AG) (Mechoulam et al. 1995; Sugiura et al. 1995). These two compounds, respectively, an amide and an ester of the $\omega-6$ arachidonic acid (Table 1), are the most active and best studied endocannabinoids (eCBs). Additional members of this family are $\omega-3$ fatty acid derivatives like $N$-eicosapentaenoylethanolamine and $\mathrm{N}$-docosahexaenoylethanolamine (Table 1); or the eCB-like compounds $\mathrm{N}$-palmitoylethanolamine and $\mathrm{N}$-oleoylethanolamine (also shown in Table 1) that do not bind to $\mathrm{CB}_{1}$ nor to $\mathrm{CB}_{2}$, but inhibit eCB degradation thus prolonging their biological activity with an "entourage effect" (Maccarrone et al. 2015,2014). AEA and 2-AG are metabolized by a complex array of biosynthetic enzymes and hydrolases, and are transported through the plasma membrane and intracellularly by distinct carriers. Altogether receptors, enzymes and transporters of eCBs form the "eCB system", that has been recently discussed in comprehensive reviews (Friedman et al. 2019; Cristino et al. 2020; Sugiura et al. 1995; Maccarrone et al. 2014; Baggelaar et al. 2018; Maccarrone 2020; Iannotti et al. 2016). The main components of the eCB system are shown in Fig. 2, and support and control the manifold actions of eCBs, both in the central nervous system (Cristino et al. 2020; Maccarrone 2020; Iannotti et al. 2016) and at the periphery (Maccarrone et al. 2015).

In particular, the number of receptors activated by eCBs in the same cell, both on the plasma membrane and in the 


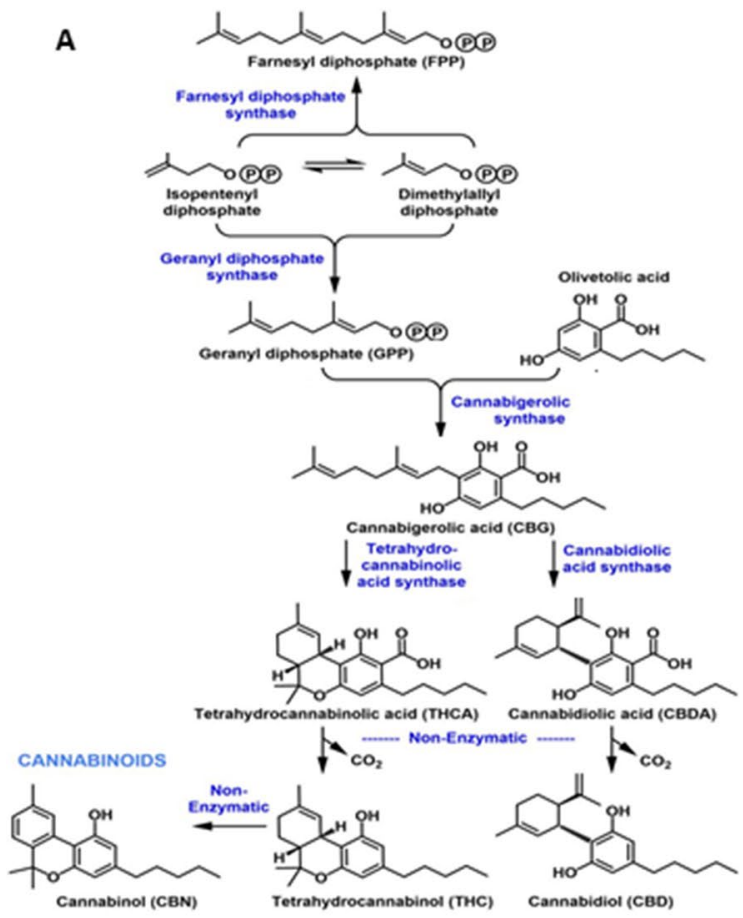

Fig. 1 Metabolism of (phyto) cannabinoids in plants. a The main steps of the biosynthesis of (phyto) cannabinoids in plants are shown, starting from farnesyl diphosphate and olivetolic acid. b Bio-

nucleus, appears striking. Indeed, these receptors include: (1) $\mathrm{CB}_{1}$ and $\mathrm{CB}_{2}$, as well as the $\mathrm{G}$ protein-coupled orphan receptor (GPR) 55 (all on the plasma membrane and with an extracellular binding site); (2) transient receptor potential vanilloid 1 (TRPV1) and additional transient receptor potential (TRP) channels (all on the plasma membrane, but with an intracellular binding site); and (3) nuclear peroxisome proliferator-activated receptors (PPARs) $\alpha, \gamma$ and $\delta$, that are all transcription factors able to regulate gene expression (Maccarrone 2020). It is of paramount importance that receptor-mediated activities of eCBs are subjected to a stringent "metabolic control", which means that their cellular concentration (and hence biological activity) depends on a balance between synthesis and degradation by different biosynthetic and hydrolytic enzymes (Friedman et al. 2019; Cristino et al. 2020; Maccarrone 2020). Among the latter, $N$-acyltransferase (NAT), $N$-acylphosphatidylethanolamines-specific phospholipase D (NAPE-PLD), along with phospholipase $\mathrm{A}_{2}\left(\mathrm{PLA}_{2}\right)$ and $\alpha / \beta$ hydrolase domain 4 (ABHD4), catalyze parallel routes for the release of AEA from phospholipid precursors; then, fatty acid amide hydrolase (FAAH) and $N$-acylethanolamine acid amidase (NAAA) cleave AEA to ethanolamine and arachidonic acid (AA), terminating its signalling (Maccarrone 2020) (Fig. 2). Much alike AEA, a phosphohydrolase $(\mathrm{PH})$ releases diacylglycerol
B

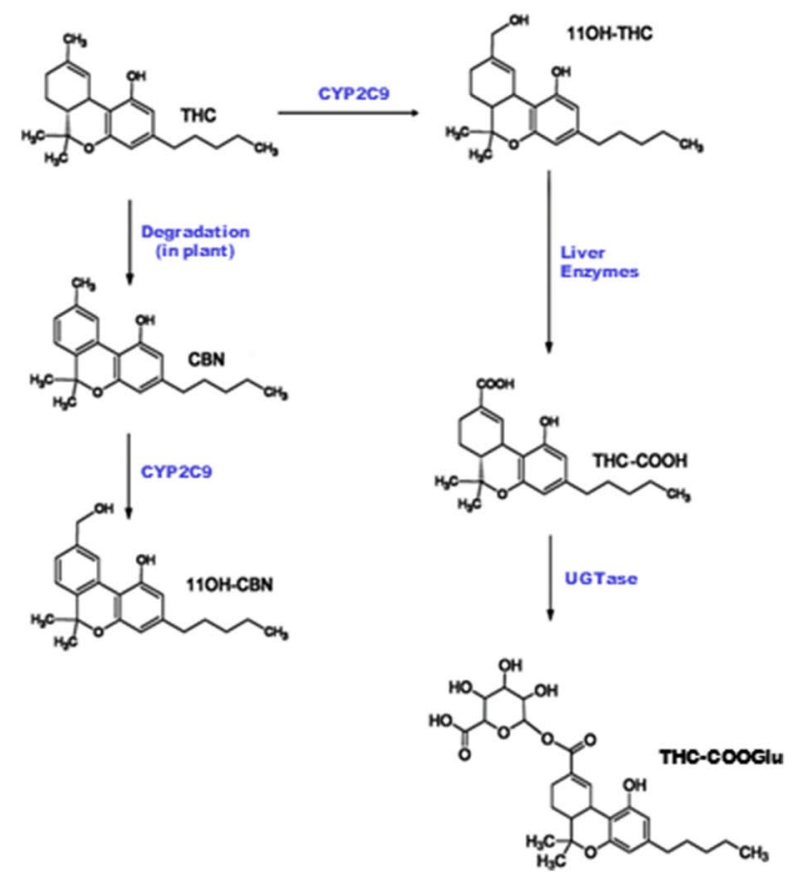

transformation of pCBs in our body by cytochrome $\mathrm{P} 450$ subfamily 2C9 (CYP2C9), liver enzymes and UDP-glucuronosyltransferase (UGTase)

(DAG) from phospholipid precursors, and DAG lipases (DAGLs) $\alpha$ and $\beta$ synthesize $2-\mathrm{AG}$ from it; then, $2-\mathrm{AG}$ is cleaved to glycerol and AA through different routes, catalysed mainly by monoacylglycerol lipase (MAGL), but also by ABHD2, ABHD6 or ABHD12 (Baggelaar et al. 2018; Maccarrone 2020) (Fig. 2). In addition to synthesis and degradation, a further level of complexity in eCB metabolism is represented by the addition of molecular oxygen to the fatty acid moiety by cyclooxygenase-2 (COX-2), various lipoxygenase isozymes and cytochrome $\mathrm{P} 450$ (Rouzer and Marnett 2011; Fezza et al. 2014). These oxidative derivatives are endowed with biological activities on their own, due to a different ability to recognize enzymes and receptors of eCBs. To date, their pathophysiological roles remain rather elusive, but apparently they include key activities like neuroprotection of the brain against excitotoxicity (Veldhuis et al. 2003). The stringent metabolic control of eCB tone is further modulated by distinct transporters that facilitate the movement of eCBs both across the plasma membrane (via a purported, as yet elusive eCB membrane transporter), and intracellularly, as well as by storage of eCBs in cytosolic organelles like adiposomes (Maccarrone 2020). 


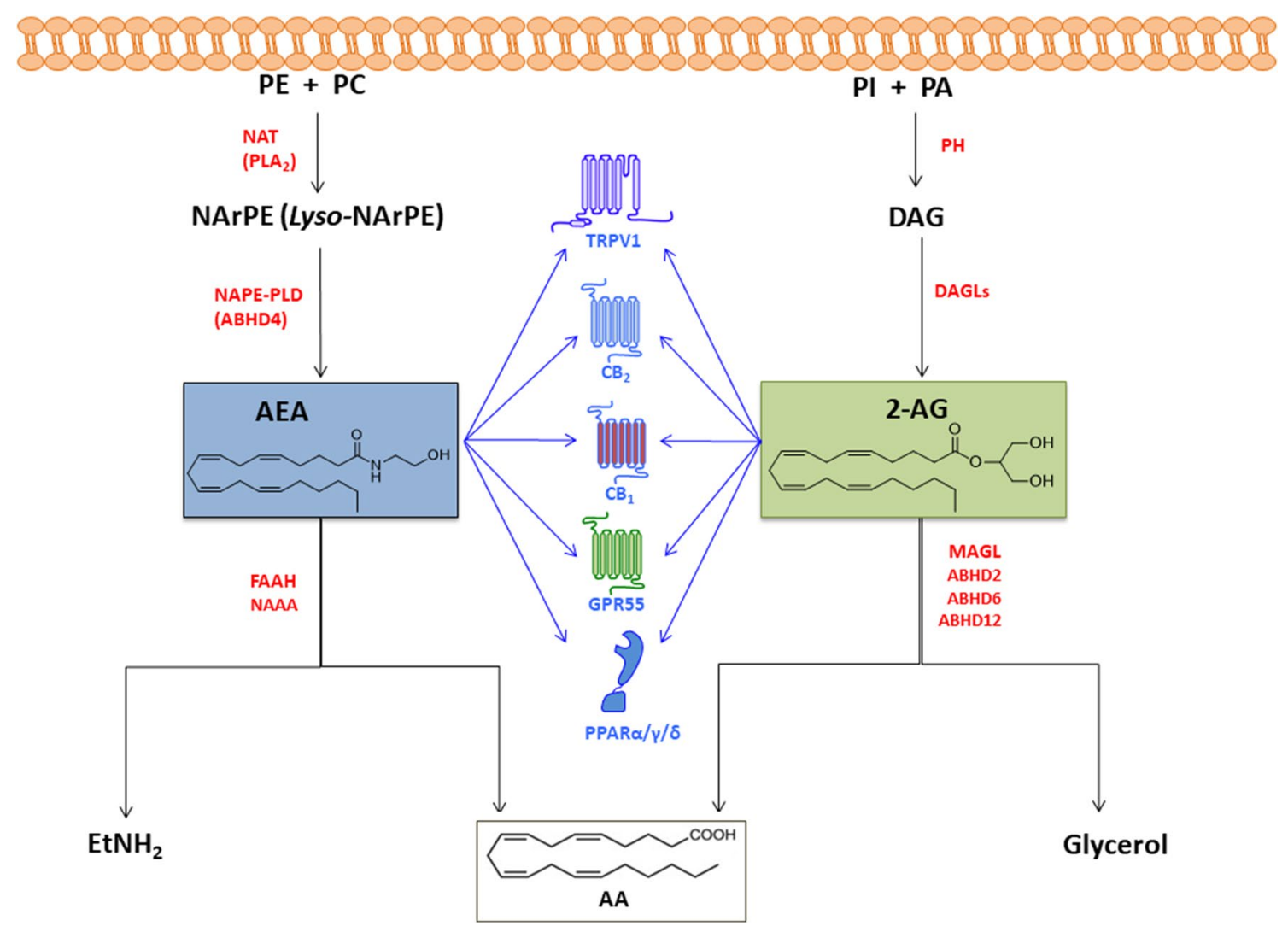

Fig. 2 Metabolism and known receptors of major endocannabinoids. For the biosynthesis of AEA, NAT produces NArPE from membrane $\mathrm{PC}$ and PE, and then NAPE-PLD releases AEA; in addition, NArPE can be converted by $\mathrm{PLA}_{2}$ into lyso-NArPE, from which ABHD4 releases AEA. 2-AG 2-Arachidonoylglycerol, $A A$ arachidonic acid, $A B H D \alpha / \beta$ hydrolase domain, $A E A N$-arachidonoyl ethanolamine, $C B$ cannabinoid receptor, $D A G$ diacylglycerol, $D A G L$ diacylglycerol lipase, $\mathrm{EtNH}_{2}$ ethanolamine $F A A H$ fatty acid amide hydrolase, $M A G L$

\section{Cross-talk between pCBs and eCBs}

Based on the observation that activities of pCBs and eCBs overlap to some extent, at the level of target receptors and/or metabolic enzymes, it remains challenging to design effective drugs based on these substances (Marzo and Piscitelli 2015; Jacobson et al. 2019). As yet, it appears that pCBs like $\Delta^{9}$-THC and $\mathrm{CBD}$ modulate $\mathrm{CB}_{1}$ and $\mathrm{CB}_{2}$ (and $\mathrm{CBD}$ does the same also at the level of TRPV1, PPARs and FAAH), whereas other pCBs like cannabidivarin and CBD acid can modulate DAGLs and COX-2 (Marzo and Piscitelli 2015). In line with this, it is well-established that chronic or recent cannabis exposure leads to down-regulation of $\mathrm{CB}_{1}$ (Jacobson et al. 2019). Unfortunately, the structural and functional properties of only a few elements of the eCB system have been thoroughly investigated (Maccarrone 2020), and this gap of knowledge must be filled to really appreciate how pCBs can interact with the eCB system, and how novel pCB/ eCB-based therapeutics can be designed against human monoacylglycerol lipase, NAAA $N$-acylethanolamine acid amidase, $N A P E-P L D N$-acyl phosphatidylethanolamines-specific phospholipase D, NArPE $N$-arachidonoyl phosphatidylethanolamine, PPAR peroxysome proliferator-activated receptor, $P A$ phosphatidic acid, $P C$ phosphatidylcholine, $P E$ phosphatidylethanolamine, $P H$ phosphohydrolase $P L A_{2}$ phospholipase $\mathrm{A}_{2}, T R P V 1$ transient receptor potential vanilloid 1

disorders. In this context, one may wonder how two so markedly different compounds like $\Delta^{9}$-THC (a terpeno-phenol) and AEA (an $\mathrm{N}$-arachidonoylethanolamine) can share common cellular targets. This apparently striking feature is due to the unanticipated similarity of their 3D structures, that indeed present three different "pharmacophores" (i.e., spatial arrangements of atoms that are essential to interact with a specific receptor target) at the same positions (Van der Stelt et al. 2002). Stereoviews of these 3D structures are shown in Fig. 3, and clearly explain why pCBs can mimic eCB biological activity.

Another interesting question arises as to whether $\mathrm{pCBs}$ appeared in nature before eCBs, or viceversa. This issue has recently found an answer, because mature black truffles (Tuber melanosporum Vittad.) were reported to contain AEA and its metabolic enzymes (Pacioni et al. 2015). It should be recalled that the botanical family of truffles (Tuberaceae) evolved during or after the first major radiation of Angiosperms in the Jurassic period (140-180 million years ago, Mya) (Soltis 


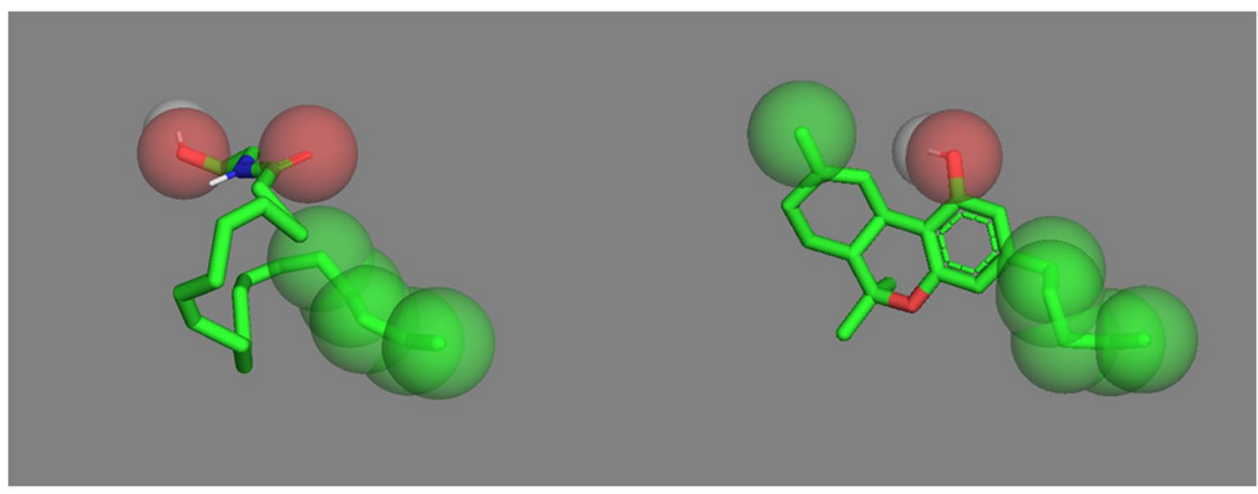

AEA

Fig. 3 Three dimensional structures of $\Delta^{9}$-THC and AEA. Stereoview of anandamide (AEA, PubChem 5281969, on the left) and $\Delta^{9}$-tetrahydrocannabinol ( $\Delta^{9}$-THC, PubChem 16078, on the right), obtained with the Pymol program (Schrodinger, www.pymol.org) to depict van der Waals surfaces of the pharmacophores and highlight corresponding positions. The center of rotation, calculated with the

et al. 2008). Instead Cannabis diverged from Humulus, both genera of the family Cannabaceae, at the end of Paleogene (28 Mya) (McPartland 2018). In keeping with these data, the phylogenetic analysis of cytochrome c oxidase subunit 1 clearly showed that $T$. melanosporum is more ancestral than C. sativa (Pacioni et al. 2015). Furthermore, a recent study on the historical biogeography of the genus Tuber has estimated its molecular dating at the end of the Jurassic period, that is 156 Mya (Bonito et al. 2013); instead, in the order Rosales, that includes the family Cannabaceae and the genus Cannabis, dates 76-107 Mya (Wikström et al. 2001; Wang et al. 2009). Incidentally, it seems interesting that many animals involved in truffle spore dispersal (e.g., nematodes, arthropoda, mammalia) possess cannabinoid receptors (Trappe and Claridge 2010; Elphick 2012), supporting the concept that AEA has an ancient role in attracting truffle eaters. In this context, it should be recalled that eCBs, unlike other eCBlike molecules devoid of activity at cannabinoid receptors, contain in their structure arachidonic acid, which has been reported in little amounts only in a few higher terrestrial plants (Shanab et al. 2018). Thus, the biosynthesis of arachidonatecontaining AEA in Tuber melanosporum remains to be further investigated. Moreover, AEA and 2-AG have been described in very simple invertebrates, such as Hydra vulgaris, which evolved earlier ( $>500$ Mya) than cannabis plant (Petrocellis et al. 1999). Finally, AEA and other $N$-acylethanolamines have also been identified in a unicellular eukaryote, such as Tetrahymena, which evolved even earlier (Karava et al. 2005; Anagnostopoulos et al. 2010).

Taken together, available evidence clearly supports the view that eCBs are "older" than $\mathrm{pCBs}$, and that the plantderived compounds took quite a few million years to mimic
Chimera program (National Institutes of Health, www.cgl.ucsf.edu), is: $\mathrm{x}=-12.68, \mathrm{y}=-3.41$ and $\mathrm{z}=-4.59$, for AEA; $\mathrm{x}=-16.89$, $y=0.23$ and $z=-3.49$, for $\Delta^{9}$-THC (method used: from center models). Carbon atoms are shown in green, oxygen atoms in red, nitrogen atoms in blue and polar hydrogen in white

the biological and pharmacological activity of our endogenous counterparts.

\section{Conclusions}

Plant-derived and endogenous cannabinoids represent two different but equally complex systems, so that the terms "(phyto) cannabinoids" and "endocannabinoids" are actually used to identify rather heterogeneous groups of lipophilic substances. It is striking how some of these molecules happened to share 3D structures, allowing exogenous $\mathrm{pCBs}$ to play so many biological activities in our body. The additional layer of complexity brought about by these structural similarities makes extremely challenging the use of pCBs as potential therapeutics to combat human diseases, and requires deeper knowledge of the structural and functional details of their potential targets in the cell. Overall, understanding these fine molecular clues will allow to turn pCBs from threats to treasure trove for human health.

Acknowledgements I wish to thank Alessandro Leuti, Emanuele Criscuolo and Maria Laura De Sciscio (Campus Bio-Medico University of Rome) for kindly preparing the artwork.

Author contributions Not applicable.

Funding Open access funding provided by Università degli Studi dell'Aquila within the CRUI-CARE Agreement. Not applicable. 


\section{Compliance with ethical standards}

Conflicts of interests Not applicable.

Open Access This article is licensed under a Creative Commons Attribution 4.0 International License, which permits use, sharing, adaptation, distribution and reproduction in any medium or format, as long as you give appropriate credit to the original author(s) and the source, provide a link to the Creative Commons licence, and indicate if changes were made. The images or other third party material in this article are included in the article's Creative Commons licence, unless indicated otherwise in a credit line to the material. If material is not included in the article's Creative Commons licence and your intended use is not permitted by statutory regulation or exceeds the permitted use, you will need to obtain permission directly from the copyright holder. To view a copy of this licence, visit http://creativecommons.org/licenses/by/4.0/.

\section{References}

Anagnostopoulos D, Rakiec C, Wood J et al (2010) Identification of endocannabinoids and related $\mathrm{N}$-acylethanolamines in Tetrahymena. A new class of compounds for Tetrahymena. Protist 161:452-465. https://doi.org/10.1016/j.protis.2009.12.004

Baggelaar MP, Maccarrone M, van der Stelt M (2018) 2-arachidonoylglycerol: a signaling lipid with manifold actions in the brain. Prog Lipid Res 71:1-17. https://doi.org/10.1016/j.plipres.2018.05.002

Bonito G, Smith ME, Nowak M et al (2013) Historical biogeography and diversification of truffles in the tuberaceae and their newly identified southern hemisphere sister lineage. PLoS ONE 8:e52765. https://doi.org/10.1371/journal.pone.0052765

Cohen K, Weizman A, Weinstein A (2019) Positive and negative effects of cannabis and cannabinoids on health. Clin Pharmacol Ther 105:1139-1147. https://doi.org/10.1002/cpt.1381

Cristino L, Bisogno T, Di Marzo V (2020) Cannabinoids and the expanded endocannabinoid system in neurological disorders. Nat Rev Neurol 16(1):9-29. https://doi.org/10.1038/s4158 2-019-0284-z

De Petrocellis L, Melck D, Bisogno T et al (1999) Finding of the endocannabinoid signalling system in Hydra, a very primitive organism: possible role in the feeding response. Neuroscience 92:377-387. https://doi.org/10.1016/s0306-4522(98)00749-0

Devane WA, Hanus L, Breuer A, Pertwee RG, Stevenson LA, Griffin G, Gibson D, Mandelbaum A, EtingerMechoulam A (1992) Isolation and structure of a brain constituent that binds to the cannabinoid receptor. Science 258:1946-1949. https://doi.org/10.1126/scien ce. 1470919

Di Marzo V, Piscitelli F (2015) The endocannabinoid system and its modulation by phytocannabinoids. Neurotherapeutics 12:692698. https://doi.org/10.1007/s13311-015-0374-6

El Sohly MA, Gul W (2014) Constituents of cannabis sativa. In: Pertwee RG (ed) Handbook of Cannabis. Oxford University press, Oxford, pp 3-22

Elphick MR (2012) The evolution and comparative neurobiology of endocannabinoid signalling. Philos Trans R Soc Lond B Biol Sci 367:3201-3215. https://doi.org/10.1098/rstb.2011.0394

ElSohly MA, Radwan MM, Gul W (2017) Phytochemistry of Cannabis sativa L. Prog Chem Org Nat Prod 103:1-36. https://doi. org/10.1007/978-3-319-45541-9_1

Fezza F, Bari M, Florio R, Talamonti E, Feole M, Maccarrone M (2014) Endocannabinoids, related compounds and their metabolic routes. Molecules 19:17078-17106. https://doi.org/10.3390/molec ules 191117078
Franco R, Rivas-Santisteban R, Reyes-Resina I, Casanovas M, PérezOlives C, Ferreiro-Vera C, Navarro G, Sánchez de Medina V, Nadal X (2020) Pharmacological potential of varinic, minor, and acidic phytocannabinoids. Pharmacol Res 158:104801. https://doi. org/10.1016/j.phrs.2020.104801

Friedman D, French JA, Maccarrone M (2019) Safety, efficacy, and mechanisms of action of cannabinoids in neurological disorders. Lancet Neurol 18:504-512. https://doi.org/10.1016/S1474 $-4422(19) 30032-8$

Hanuš LO, Meyer SM, Muñoz E, Taglialatela-Scafati O, Appendino G (2016) Phytocannabinoids: a unified critical inventory. Nat Prod Rep 33:1357-1392. https://doi.org/10.1039/c6np00074f

Iannotti FA, Di Marzo V, Petrosino S (2016) Endocannabinoids and endocannabinoid-related mediators: targets, metabolism and role in neurological disorders. Prog Lipid Res 62:107-128. https://doi. org/10.1016/j.plipres.2016.02.002

Jacobson MR, Watts JJ, Boileau I, Tong J, Mizrahi R (2019) A systematic review of phytocannabinoid exposure on the endocannabinoid system: implications for psychosis. Eur Neuropsychopharmacol 29:330-348. https://doi.org/10.1016/j.euroneuro.2018.12.014

Karava V, Zafiriou PM, Fasia L et al (2005) Anandamide metabolism by Tetrahymena pyriformis in vitro. Characterization and identification of a $66 \mathrm{kDa}$ fatty acid amidohydrolase. Biochimie 87:967-974. https://doi.org/10.1016/j.biochi.2005.04.011

Ligresti A, De Petrocellis L, Di Marzo V (2016) From phytocannabinoids to cannabinoid receptors and endocannabinoids: pleiotropic physiological and pathological roles through complex pharmacology. Physiol Rev 96:1593-1659. https://doi. org/10.1152/physrev.00002.2016

Maccarrone M (2020) Missing pieces to the endocannabinoid puzzle. Trends Mol Med 26:263-272. https://doi.org/10.1016/j.molme d.2019.11.002

Maccarrone M, Guzmán M, Mackie K, Doherty P, Harkany T (2014) Programming of neural cells by (endo) cannabinoids: from physiological rules to emerging therapies. Nat Rev Neurosci 15:786-801. https://doi.org/10.1038/nrn3846

Maccarrone M, Bab I, Bíró T, Cabral GA, Dey SK, Di Marzo V, Konje JC, Kunos G, Mechoulam R, Pacher P, Sharkey KA, Zimmer A (2015) Endocannabinoid signaling at the periphery: 50 years after THC. Trends Pharmacol Sci 36(5):277-296. https:// doi.org/10.1016/j.tips.2015.02.008

McPartland JM (2018) Cannabis systematics at the levels of family, genus, and species. Cannabis Cannabinoid Res 3:203-212. https ://doi.org/10.1089/can.2018.0039

Mechoulam R, Ben-Shabat S, Hanus L, Ligumsky M, Kaminski NE, Schatz AR, Gopher A, Almog S, Martin BR, Compton DR (1995) Identification of an endogenous 2-monoglyceride, present in canine gut, that binds to cannabinoid receptors. Biochem Pharmacol 50:83-90. https://doi.org/10.1016/00062952(95)00109-d

Morales P, Hurst DP, Reggio PH (2017) Molecular targets of the phytocannabinoids: a complex picture. Prog Chem Org Nat Prod 103:103-131. https://doi.org/10.1007/978-3-319-45541-9_4

Pacioni G, Rapino C, Zarivi O et al (2015) Truffles contain endocannabinoid metabolic enzymes and anandamide. Phytochemistry 110:104-110. https://doi.org/10.1016/j.phytochem.2014.11.012

Pertwee RG (2014) Handbook of cannabis. Oxford University press, Oxford

Rouzer CA, Marnett LJ (2011) Endocannabinoid oxygenation by cyclooxygenases, lipoxygenases, and cytochromes P450: cross-talk between the eicosanoid and endocannabinoid signaling pathways. Chem Rev 111(10):5899-5921. https://doi. org/10.1021/cr2002799

Russo EB (2018) Cannabis therapeutics and the future of neurology. Front Integr Neurosci 12:51. https://doi.org/10.3389/fnint .2018 .00051 
Schafroth MA, Carreira EM (2017) Synthesis of phytocannabinoids. Prog Chem Org Nat Prod 103:37-59. https://doi. org/10.1007/978-3-319-45541-9_2

Shanab SMM, Hafez RM, Fouad AS (2018) A review on algae and plants as potential source of arachidonic acid. J Adv Res 11:313. https://doi.org/10.1016/j.jare.2018.03.004

Soltis DE, Bell CD, Kim S, Soltis PS (2008) Origin and early evolution of angiosperms. Ann NY Acad Sci 1133:3-25. https://doi. org/10.1196/annals.1438.005

Solymosi K, Köfalvi A (2017) Cannabis: a treasure trove or Pandora's box? Mini Rev Med Chem 17:1223-1291. https://doi. org/10.2174/1389557516666161004162133

Sugiura T, Kondo S, Sukagawa A, Nakane S, Shinoda A, Itoh K, Yamashita A, Waku K (1995) 2-Arachidonoylglycerol: a possible endogenous cannabinoid receptor ligand in brain. Biochem Biophys Res Commun 215:89-97. https://doi.org/10.1006/ bbrc. 1995.2437

Trappe JM, Claridge AW (2010) The hidden life of truffles. Sci Am 302(78-82):84. https://doi.org/10.1038/scientificamerican04 $10-78$

Turner SE, Williams CM, Iversen L, Whalley BJ (2017) Molecular pharmacology of phytocannabinoids. Prog Chem Org Nat Prod 103:61-101. https://doi.org/10.1007/978-3-319-45541-9_3

United Nations office on drugs and crime (2017). https://www.unodc .org/wdr2017/field/Booklet_1 EXSUM.pdf

van der Stelt M, van Kuik JA, Bari M et al (2002) Oxygenated metabolites of anandamide and 2-arachidonoylglycerol: conformational analysis and interaction with cannabinoid receptors, membrane

\section{Affiliations}

\section{Mauro Maccarrone ${ }^{1,2}$}

Mauro Maccarrone

mauro.maccarrone@univaq.it

1 Department of Applied Clinical and Biotechnological Sciences, University of L'Aquila, Via Vetoio,

67100 L'Aquila, Italy transporter, and fatty acid amide hydrolase. J Med Chem 45:3709_ 3720. https://doi.org/10.1021/jm020818q

Veldhuis WB, van der Stelt M, Wadman MW et al (2003) Neuroprotection by the endogenous cannabinoid anandamide and arvanil against in vivo excitotoxicity in the rat: role of vanilloid receptors and lipoxygenases. J Neurosci 23:4127-4133. https://doi. org/10.1523/JNEUROSCI.23-10-04127.2003

Wang H, Moore MJ, Soltis PS et al (2009) Rosid radiation and the rapid rise of angiosperm-dominated forests. Proc Natl Acad Sci USA 106:3853-3858. https://doi.org/10.1073/pnas.0813376106

Watanabe K, Narimatsu S, Matsunaga T, Yamamoto I, Yoshimura H (1993) A cytochrome P450 isozyme having aldehyde oxygenase activity plays a major role in metabolizing cannabinoids by mouse hepatic microsomes. Biochem Pharmacol 46:405-411. https://doi. org/10.1016/0006-2952(93)90516-y

Watanabe K, Yamaori S, Funahashi T, Kimura T, Yamamoto I (2007) Cytochrome P450 enzymes involved in the metabolism of tetrahydrocannabinols and cannabinol by human hepatic microsomes. Life Sci 80:1415-1419. https://doi.org/10.1016/j.lfs.2006.12.032

Wikström N, Savolainen V, Chase MW (2001) Evolution of the angiosperms: calibrating the family tree. Proc Biol Sci 268:2211-2220. https://doi.org/10.1098/rspb.2001.1782

Publisher's Note Springer Nature remains neutral with regard to jurisdictional claims in published maps and institutional affiliations. European Center for Brain Research, IRCCS Santa Lucia Foundation, Via del Fosso di Fiorano 64, 00143 Rome, Italy 